\title{
Monitoring Boundary Currents Using Ocean Observing Infrastructure
}

By Tamaryn Morris, Daniel Rudnick, Janet Sprintall, Juliet Hermes, Gustavo J. Goni, Justine Parks, Francis Bringas,
Emma Heslop, and the numerous contributors to the OCG-12 Boundary Current Workshop and OceanGliders BOON Project

Boundary currents dominate the poleward transport of warm water and the equatorward transport of cold water and are major drivers of climate variability, extreme weather events (e.g.,hurricanes), and marine heatwaves (Figure 1). The western boundary regions have some of the most dynamic and energetic currents in the ocean and are key to the transport of mass, heat, salt, biogeochemical properties, and plankton. The eastern boundary currents are often upwelling systems that comprise some of the most biologically productive regions in the world. Boundary currents in marginal seas provide the major means of exchange with the open ocean and impact regional ecosystems. Communication between the coast and open ocean is regulated by the boundary currents that flow along the continental slopes, affecting ecosystems, sea level, flood levels, erosion, and commercial activity.
Current strategies used to monitor boundary currents vary and are composed of individual and partially coordinated efforts. At global scales, the Argo array of profiling floats collects a growing suite of ocean physical and biogeochemical parameters, providing comprehensive coverage offshore of the continental shelf. Satellite measurements of sea surface height, temperature, salinity, and ocean color clearly identify the signals of mesoscale features at the ocean surface. Surface drifters take measurements of currents (e.g., Figure 2). The need for finer spatial and temporal resolution closer to shore is addressed with more regionally focused efforts (Figure 3). Ocean gliders provide sustained or targeted observations across a few boundary current systems that connect the coast to the open ocean. The OceanSites network of moorings has some of the longest in situ time series at strategic locations within boundary currents. The high-density/ resolution expendable bathythermograph network provides repeat temperature sections with fine spatial resolution across selected boundary currents along with seasonal sampling. Each network in the Global Ocean Observing System provides observations that complement each other in their efforts to monitor boundary currents. Further expansion of the suite of observing platforms may come from technologies such as autonomous surface vehicles.
FIGURE 1. Major global ocean currents. White indicates warm western boundary currents, with the cooler eastern boundary currents in blue. Equatorial currents (red) and the Antarctic Circumpolar Current (purple) are shown for reference only. Potential sea surface temperature map was made available by Copernicus Marine Service through their MyOcean visualization web portal.

FIGURE 2. Trajectories and nearsurface velocity estimates from Global Drifter Program drifters in the western Pacific and marginal seas. Paths of various boundary currents are clearly visible. From

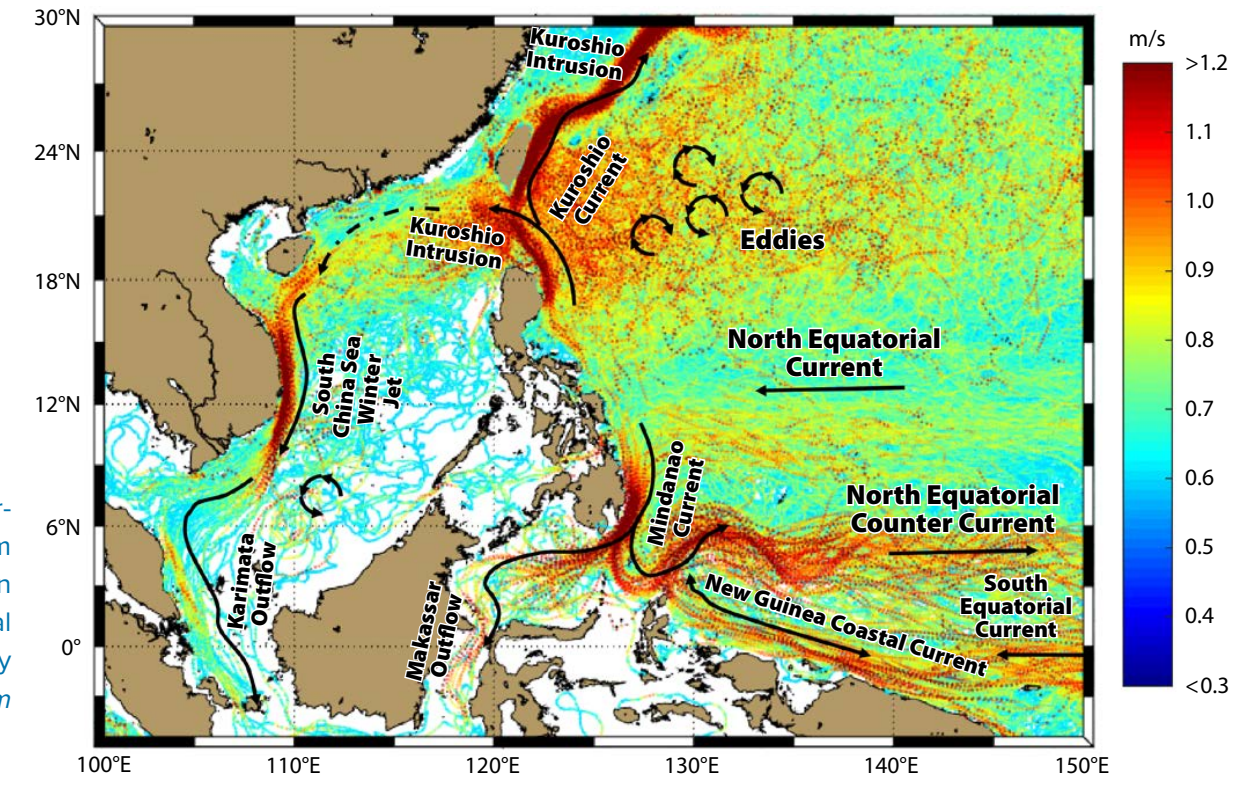


FIGURE 3. Example of a potential coastal ocean observing network that uses multiple technologies to gather data. Instruments associated with the Ships of Opportunity Program, such as expendable bathythermographs, thermosalinographs, and Continuous Plankton Recorders, are not shown. From OceanOps (c) Thomas Haessig

Todd et al. (2019) provide details of the current and proposed internationally coordinated system for monitoring boundary currents globally. Individual components of an effective boundary current observing system will depend on the current being monitored and its water mass properties and dynamics, and the societal, weather, and ecosystem impacts that need to be addressed. An example of where cross-network observations would be of use is to study the little understood phenomena of marine heatwaves (MHWs). With an increase in ocean heat content over the last two decades, MHWs have increased in intensity and frequency globally, particularly within the equatorial regions and western and eastern boundary current systems. MHWs are extreme climatic events that can have devastating impacts on ocean services, such as fisheries and mariculture farming, can cause major coral bleaching events resulting in a loss of biodiversity, and can intensify tropical cyclone (hurricane) systems due to the increase in sea surface temperatures (Frölicher and Laufkötter, 2018; Saranya et al., 2021). As an example, an MHW caused intensification of tropical cyclone Amphan from a category 1 to a category 5 superstorm in a little over 18 hours, which caused massive devastation in both India and Bangladesh (Saranya et al., 2021). Yet, these phenomena, their driving forces and seasonality, and their connectivity between ocean basins remain largely unknown. Sustained ocean observing systems in boundary currents systems, using a wide variety of instrument types, would go a long way toward improving our understanding of MHWs.

Several boundary currents reside within countries' Exclusive Economic Zones. Observing boundary currents will, therefore, depend on regional efforts and cooperation. Regional pilot studies have been suggested as a mechanism for investigating the cross-platform use of ocean observing systems to monitor particularly understudied boundary currents. Crucial to this effort would be interacting with regional stakeholders to understand

their needs and challenges. In this way, a fit-for-purpose, multi-instrument, multivariable monitoring system can be designed, tested, and implemented.

As the ocean continues to absorb more heat and carbon dioxide from the atmosphere, sustained ocean observing, particularly within boundary currents that drive regional climate variability, is critical for understanding the varied impacts these ocean changes can bring about and for preparing coastal communities for the associated risks. To paraphrase an old African proverb, "If you want to go fast, go alone. If you want to go far, go together." Studying these highly dynamic ocean regions effectively requires a strategy that includes global cooperation in the deployment of observing platforms, with relevant user groups regionally responding to the needs and challenges of their communities and stakeholders.

\section{REFERENCES}

Frölicher, T.L., and C. Laufkötter. 2018. Emerging risks from marine heat waves. Nature Communications 9, 650, https://doi.org/10.1038/ s41467-018-03163-6.

Saranya, J.S., R.M. Koll, P. Dasgupta, and A. Anand. 2021. Genesis and trends in marine heatwaves over the tropical Indian Ocean and their interaction with the Indian summer monsoon. Earth and Space Science Open Archive 38, https://doi.org/10.1002/essoar.10506673.3.

Todd, R.E., D.L. Rudnick, L.R. Centurioni, S.R. Jayne, and C.M. Lee. 2018 Boundary current observations with ALPS. Pp. 47-49 in D. Rudnick, D. Costa, K. Johnson, C. Lee, and M.-L. Timmermans, eds. 2018. ALPS // - Autonomous Lagrangian Platforms and Sensors. A Report of the ALPS II Workshop, February 21-24, La Jolla, CA, https://geo-prose.com/alps-ii. Todd, R.E., F.P. Chavez, S. Clayton, S. Cravatte, M. Goes, M. Graco, X. Lin, J. Sprintall, N.V. Zilberman, M. Archer, and others. 2019. Global perspectives on observing ocean boundary current systems. Frontiers in Marine Science 6:423, https://doi.org/10.3389/fmars.2019.00423.

ARTICLE DOI: https://doi.org/10.5670/oceanog.2021.supplement.02-07 


\section{AUTHORS}

Tamaryn Morris (tamaryn.morris@weathersa.co.za), South African Weather Service (SAWS), South Africa. Daniel Rudnick, Janet Sprintall, and Justine Parks, Scripps Institution of Oceanography, University of California San Diego, USA. Juliet Hermes, South African Environmental Observation Network (SAEON), South Africa. Gustavo J. Goni and Francis Bringas, NOAA Atlantic Oceanographic and Meteorological Laboratory, USA. Emma Heslop, IOC/UNESCO, France. And the numerous contributors to the OCG-12 Boundary Current Workshop and OceanGliders BOON Project.

\section{ARTICLE CITATION}

Morris, T., D. Rudnick, J. Sprintall, J. Hermes, G. J. Goni, J. Parks, F. Bringas, E. Heslop, and the numerous contributors to the OCG-12 Boundary Current Workshop and OceanGliders BOON Project. 2021. Monitoring boundary currents using ocean observing infrastructure. Pp. 16-17 in Frontiers in Ocean Observing: Documenting Ecosystems, Understanding Environmental Changes, Forecasting Hazards. E.S. Kappel, S.K. Juniper, S. Seeyave, E. Smith, and M. Visbeck, eds, A Supplement to Oceanography 34(4), https://doi.org/10.5670/oceanog.2021.supplement.02-07.

\section{COPYRIGHT \& USAGE}

This is an open access article made available under the terms of the Creative Commons Attribution 4.0 International License (https://creativecommons.org/ licenses/by/4.0/), which permits use, sharing, adaptation, distribution, and reproduction in any medium or format as long as users cite the materials appropriately, provide a link to the Creative Commons license, and indicate the changes that were made to the original content. 